\title{
\begin{tabular}{l|l} 
Mitraries & DSpace@MIT
\end{tabular}
}

\author{
MIT Open Access Articles
}

\section{Palladium-Catalyzed Alkyl-Alkyl Suzuki Cross-Couplings of Primary Alkyl Bromides at Room Temperature}

The MIT Faculty has made this article openly available. Please share how this access benefits you. Your story matters.

Citation: Lou, Sha and Gregory C. Fu. "Palladium-Catalyzed Alkyl-Alkyl Suzuki Cross-Couplings of Primary Alkyl Bromides at Room Temperature." Organic Syntheses, 2010, 87, 299-309.

As Published: http://www.orgsyn.org/orgsyn/orgsyn/prepContent.asp?

rxntypeid=463\&prep=v87p0299

Publisher: John Wiley \& Sons, Inc.

Persistent URL: http://hdl.handle.net/1721.1/67650

Version: Author's final manuscript: final author's manuscript post peer review, without publisher's formatting or copy editing

Terms of use: Creative Commons Attribution-Noncommercial-Share Alike 3.0 


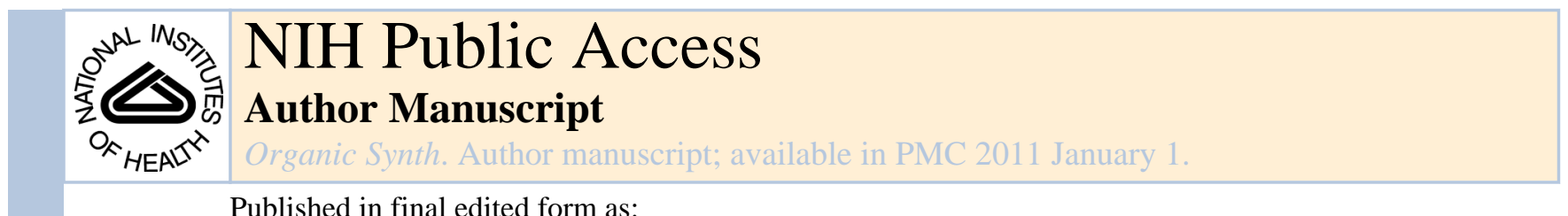

Organic Synth. 2010 January 1; 87: 299.

\section{PALLADIUM-CATALYZED ALKYL-ALKYL SUZUKI CROSS- COUPLINGS OF PRIMARY ALKYL BROMIDES AT ROOM- TEMPERATURE: (13-CHLOROTRIDECYLOXY)TRIETHYLSILANE [Silane, [(13-chlorotridecyl)oxy]triethyl-]}

Sha Lou, Gregory C. Fu, Takuyo Higo, and Tohru Fukuyama

\section{Procedure}

\section{A. 1-Bromo-8-chlorooctane (1)}

An oven-dried, 200-mL, two-necked, round-bottomed flask equipped with an argon inlet and a magnetic stir bar (octagonal, molded pivot ring, $25 \mathrm{~mm}$ length and $6 \mathrm{~mm}$ diameter) is purged with argon for $5 \mathrm{~min}$ and then charged through the open neck with $\mathrm{CH}_{2} \mathrm{Cl}_{2}(50 \mathrm{~mL}$ via syringe) (Note 1), imidazole ( $2.19 \mathrm{~g}, 32.1 \mathrm{mmol}, 1.10$ equiv) (Note 2$)$, and dichlorotriphenylphosphorane ( $10.4 \mathrm{~g}, 31.2 \mathrm{mmol}, 1.07$ equiv) (Note 3$)$. The open neck is capped with a rubber septum, and the stirred solution is cooled in an ice bath for $5 \mathrm{~min}$. A solution of 8-bromo-1-octanol (5.0 mL, $6.11 \mathrm{~g}, 29.2 \mathrm{mmol}, 1.00$ equiv) (Note 4) in $\mathrm{CH}_{2} \mathrm{Cl}_{2}$ $(10 \mathrm{~mL})$ (Note 1) is added via syringe over $5 \mathrm{~min}$. The reaction mixture is allowed to warm to rt, and the resulting heterogeneous solution (a white precipitate formed) is stirred for $4 \mathrm{~h}$. The progress of the reaction is followed by TLC analysis on $\mathrm{SiO}_{2}(10 \% \mathrm{EtOAc} / \mathrm{hexanes}$ as the eluent; visualization with a $\mathrm{KMnO}_{4}$ stain; the alcohol starting material has an $\mathrm{R}_{f}=0.2$, and the chloride product has an $\mathrm{R}_{f}=0.9$ ) (Note 5). After the alcohol is consumed, the reaction is diluted with pentane $(200 \mathrm{~mL})$, and the mixture is filtered through a pad of $\mathrm{SiO}_{2}$ (7 cm diameter $\times 6 \mathrm{~cm}$ height) in a sintered glass funnel. $\mathrm{The}_{\mathrm{SiO}_{2}}$ is washed with additional pentane $(400 \mathrm{~mL})$. The filtrate is concentrated by rotary evaporation $\left(20 \mathrm{mmHg}, 30^{\circ} \mathrm{C}\right)$, which furnishes the desired product as a colorless oil (6.23-6.44 g, 94-97 \% yield) (Note 6). The product is used in the next step without further purification.

\section{B. Triethyl(pent-4-enyloxy)silane (2)}

An oven-dried, 200-mL, two-necked, round-bottomed flask equipped with an argon inlet and a magnetic stirbar (octagonal, molded pivot ring, $25 \mathrm{~mm}$ length and $6 \mathrm{~mm}$ diameter) is

Safety and Waste Disposal Information

All hazardous materials should be handled and disposed of in accordance with "Prudent Practices in the Laboratory"; National Academy Press; Washington, DC, 1995.

${ }^{1}$ Dichloromethane (>99.5\%) was purchased from Kanto Chemical Co., Inc. (water content $<0.001 \%$ ) and purified by Glass Contour solvent systems. The submitters purchased dichloromethane (>99.8\%) from J.T. Baker (water content $<0.02 \%$ ), which was purified by passage through activated alumina under argon.

${ }^{2}$ Imidazole (99\%) was purchased from Alfa Aesar and used as received.

${ }^{3}$ Dichlorotriphenylphosphorane (95\%) was purchased from Aldrich and used as received.

48 -Bromo-1-octanol (95\%) was purchased from Alfa Aesar and used as received.

${ }^{5}$ Analytical thin-layer chromatography was performed using Merck silica gel 60 F254 plates $(0.25 \mathrm{~mm})$.

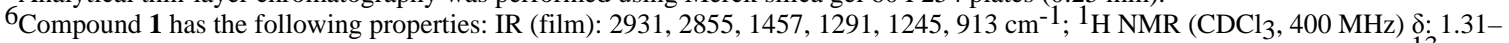
$1.35(\mathrm{~m}, 4 \mathrm{H}), 1.40-1.47(\mathrm{~m}, 4 \mathrm{H}), 1.75-1.81(\mathrm{~m}, 2 \mathrm{H}), 1.82-1.89(\mathrm{~m}, 2 \mathrm{H}), 3.41(\mathrm{t}, J=7.0 \mathrm{~Hz}, 2 \mathrm{H}), 3.54(\mathrm{t}, J=7.0 \mathrm{~Hz}, 2 \mathrm{H}) ;{ }^{13} \mathrm{C}$ $\mathrm{NMR}\left(\mathrm{CDCl}_{3}, 100 \mathrm{MHz}\right) \delta: 26.7,28.0,28.6,28.7,32.5,32.7,34.0,45.1$; Anal. Calcd. for $\mathrm{C}_{8} \mathrm{H}_{17} \mathrm{BrCl}$ : C, 42.22; $\mathrm{H}, 7.09$; $\mathrm{N}$, 0; found: $\mathrm{C}, 41.94 ; \mathrm{H}, 6.85 ; \mathrm{N}, 0$. The spectral data are in agreement with the reported values. ${ }^{2}$ Compound $\mathbf{1}$ can be purified via column chromatography on $\mathrm{SiO}_{2}$, eluting with pentane $\left(\mathrm{R}_{f}=0.6\right.$, pentane; visualization with $\left.\mathrm{KMnO}_{4}\right)$. 
purged with argon for 5 min and then charged through the open neck with $N, N$ dimethylformamide ( $50 \mathrm{~mL}$ via syringe) (Note 7), 4-penten-1-ol ( $8.93 \mathrm{~mL}$ via syringe, 7.50 g, $87.1 \mathrm{mmol}, 1.00$ equiv) (Note 8), and imidazole (5.93 g, $87.1 \mathrm{mmol}, 1.00$ equiv) (Note 2). The open neck is capped with a rubber septum. The stirred solution is cooled in an ice bath for $5 \mathrm{~min}$, and then chlorotriethylsilane (14.6 mL, $13.1 \mathrm{~g}, 87.1 \mathrm{mmol}, 1.00$ equiv) (Note 9) is added over 4 min via syringe. The reaction mixture is stirred at $\mathrm{rt}$ for $24 \mathrm{~h}$. The progress of the reaction is followed by TLC analysis on $\mathrm{SiO}_{2}(20 \% \mathrm{EtOAc} /$ hexanes as the eluent; visualization with a $\mathrm{KMnO}_{4}$ stain; the alcohol starting material has an $\mathrm{R}_{f}=0.2$, and the silyl ether product has an $\mathrm{R}_{f}=0.7$ ) (Note 5). After the alcohol has been consumed, the reaction mixture is poured into a mixture of pentane $(300 \mathrm{~mL})$ and water $(60 \mathrm{~mL})$ in a $500-\mathrm{mL}$ separatory funnel. The organic layer is separated and washed with brine $(3 \times 50 \mathrm{~mL})$. The organic solution is dried over $\mathrm{MgSO}_{4}(30 \mathrm{~g})$ and then vacuum filtered through a Büchner funnel containing a bed of celite $(1.0 \mathrm{~cm}$ height). The filtrate is concentrated by rotary evaporation $\left(20 \mathrm{mmHg}, 30{ }^{\circ} \mathrm{C}\right)$, and the residue is transferred to a $50-\mathrm{mL}$ round-bottomed flask equipped with a magnetic stirbar (octagonal, molded pivot ring, $15 \mathrm{~mm}$ length and 7 $\mathrm{mm}$ diameter) and a short-path distillation head. The residue is distilled under vacuum (bp $77-79^{\circ} \mathrm{C}$ at $8 \mathrm{mmHg}$ ), which provides the desired silyl ether $\mathbf{2}$ as a colorless oil (15.2-15.7 $\mathrm{g}, 87-90 \%$ yield) (Note 10$)$.

\section{C. (5-(9-Borabicyclo[3.3.1]nonan-9-yl)pentyloxy)triethylsilane (3)}

An oven-dried, 200-mL, round-bottomed flask equipped with an argon inlet and a magnetic stirbar (octagonal, molded pivot ring, $25 \mathrm{~mm}$ length and $6 \mathrm{~mm}$ diameter) is purged with argon for $10 \mathrm{~min}$. The open neck is capped with a rubber septum, and then a solution of 9borabicyclo[3.3.1]nonane (9-BBN; $0.50 \mathrm{M}$ in THF; $72 \mathrm{~mL}, 36 \mathrm{mmol}, 1.0$ equiv) (Note 11) is added via syringe. Next, triethyl(pent-4-enyloxy)silane (2) (7.21 g, $36.0 \mathrm{mmol}, 1.0$ equiv) is added via syringe over $3 \mathrm{~min}$ to the solution of 9-BBN. The reaction mixture is stirred for 3 $\mathrm{h}$, at which time all of the starting olefin is consumed as determined by TLC analysis (pentane as the eluent; visualization with a $\mathrm{KMnO}_{4}$ stain; the olefin starting material has an $\mathrm{R}_{f}=0.2$ ) (Note 5). This solution is used directly in the next step.

\section{D. (13-Chlorotridecyloxy)triethylsilane (4)}

An oven-dried, 1000-mL, three-necked, round-bottomed flask equipped with a thermometer inlet, a thermometer, a magnetic stir bar (octagonal, molded pivot ring, $40 \mathrm{~mm}$ length and 10 $\mathrm{mm}$ diameter), and an argon inlet is purged with argon for $10 \mathrm{~min}$. Palladium(II) acetate (270 mg, $1.20 \mathrm{mmol}, 0.040$ equiv) (Note 12), tricyclohexylphosphine (673 mg, $2.40 \mathrm{mmol}$, 0.080 equiv) (Note 13), and tripotassium phosphate, monohydrate $\left(\mathrm{K}_{3} \mathrm{PO}_{4} \cdot \mathrm{H}_{2} \mathrm{O} ; 8.28 \mathrm{~g}, 36.0\right.$ mmol, 1.2 equiv) (Note 14) are added through the open neck of the flask. Then, the open neck is capped with a rubber septum, and the solution of (5-(9-borabicyclo[3.3.1]nonan-9yl)-pentyloxy)triethylsilane (3) prepared in Step C (36 mmol, 1.2 equiv) is added to the flask via syringe, followed by the addition of 1-bromo-8-chlorooctane (1) $(6.83 \mathrm{~g}, 30.0 \mathrm{mmol}, 1.0$

\footnotetext{
${ }^{7} N, N$-Dimethylformamide (>99.5) was purchased from Wako Pure Chemical Industries, Ltd. and used as received. The submitters purchased $N, N$-Dimethylformamide (ACS reagent grade) from MP Biomedicals, LLC and used it as received.

8-Penten-1-ol $(98+\%)$ was purchased from Alfa Aesar and used as received.

${ }^{9}$ Chlorotriethylsilane $(98+\%)$ was purchased from Alfa Aesar and used as received.

${ }^{10}$ Compound 2 has the following properties: IR (film): 2947, 2884, 2826, 1653, 1457, 1418, 1015, $743 \mathrm{~cm}^{-1} ;{ }^{1} \mathrm{H}_{\mathrm{NMR}}\left(\mathrm{CDCl}_{3}, 400\right.$ MHz) $\delta: 0.60(\mathrm{q}, J=8.0 \mathrm{~Hz}, 6 \mathrm{H}), 0.96(\mathrm{t}, J=8.0 \mathrm{~Hz}, 9 \mathrm{H}), 1.60-1.66(\mathrm{~m}, 2 \mathrm{H}), 2.11(\mathrm{q}, J=6.8 \mathrm{~Hz}, 2 \mathrm{H}), 3.62(\mathrm{t}, J=6.4 \mathrm{~Hz}, 2 \mathrm{H})$, 4.94-5.05 (m, $2 \mathrm{H}), 5.79-5.86(\mathrm{~m}, 1 \mathrm{H}) ;{ }^{13} \mathrm{C} \mathrm{NMR}\left(\mathrm{CDCl}_{3}, 100 \mathrm{MHz}\right) \delta: 4.4,6.8,30.1,32.0,62.3,114.5,138.5$; LRMS (DART) $\mathrm{m} / z$ calcd. for $\mathrm{C}_{11} \mathrm{H}_{25} \mathrm{OSi}\left([\mathrm{M}+\mathrm{H}]^{+}\right)$201.2; found 201.2. The spectral data are in agreement with the reported values. ${ }^{2}$

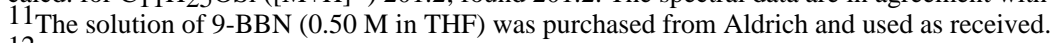

${ }_{12} \mathrm{Pd}(\mathrm{OAc}) 2(99+\%)$ was purchased from Strem and used as received.

$13 \mathrm{PCy}_{3}(97 \%)$ was purchased from Strem and used as received.

14 Tripotassium phosphate, monohydrate $(\geq 94 \%)$ was purchased from Fluka and used as received. When anhydrous tripotassium phosphate is employed, essentially no cross-coupling is observed.
} 
equiv). The resulting dark-brown heterogeneous reaction mixture is stirred vigorously at $\mathrm{rt}$ for $24 \mathrm{~h}$. The progress of the reaction is followed by TLC analysis on $\mathrm{SiO}_{2}\left(25 \% \mathrm{CH}_{2} \mathrm{Cl}_{2} /\right.$ hexanes as the eluent; visualization with a $\mathrm{KMnO}_{4}$ stain; the alkyl bromide starting material has an $\mathrm{R}_{f}=0.5$, and the cross-coupling product has an $\mathrm{R}_{f}=0.4$ ) (Note 5). Next, the mixture is diluted with diethyl ether $(200 \mathrm{~mL})$ and filtered through a sintered glass funnel containing $\mathrm{SiO}_{2}\left(7.0 \mathrm{~cm}\right.$ diameter $\times 5.0 \mathrm{~cm}$ height). The $\mathrm{SiO}_{2}$ is washed with additional diethyl ether $(200 \mathrm{~mL})$, and the combined filtrate is concentrated by rotary evaporation $(20 \mathrm{mmHg}, 30$ $\left.{ }^{\circ} \mathrm{C}\right)$. The residue is purified by column chromatography on $\mathrm{SiO}_{2}$ (Note 15). The desired cross-coupling product 4 has $\mathrm{R}_{f}=0.7$ (TLC analysis on $\mathrm{SiO}_{2}: 50 \% \mathrm{CH}_{2} \mathrm{Cl}_{2} /$ hexanes as eluent, visualization with $\mathrm{KMnO}_{4}$ ) (Note 5). The cross-coupling product is obtained as a pale-yellow oil (9.63-10.10 g, 92-96\% yield) (Note 16).

\title{
3. Discussion
}

The palladium-catalyzed coupling of organometallic compounds with aryl and vinyl halides is a now-classic method for carbon-carbon bond formation. ${ }^{3}$ In contrast, until recently, the corresponding reactions of alkyl halides were relatively uncommon. ${ }^{3}$ Slow oxidative addition and facile $\beta$-hydride elimination have been suggested as two of the possible culprits for this comparative lack of success (Scheme 1). With respect to the Suzuki reaction, prior to 2001 only one somewhat general method had been described for achieving cross-couplings of unactivated, $\beta$-hydrogen containing alkyl electrophiles, specifically, a $\mathrm{Pd}\left(\mathrm{PPh}_{3}\right)_{4}$ catalyzed process for coupling alkyl iodides. ${ }^{5}$

We have determined that, through the appropriate choice of ligand, palladium-catalyzed Suzuki cross-couplings can be accomplished with an array of unactivated alkyl bromides, chlorides, and tosylates that bear $\beta$ hydrogens. $2,6,{ }^{7}$ Specifically, bulky electron-rich trialkylphosphines furnish particularly active catalysts. For example, in the case of alkyl bromides, $\mathrm{Pd}(\mathrm{OAc})_{2} / \mathrm{PCy}_{3}$ achieves the desired coupling under mild conditions (room temperature; Table 1). The process is compatible with a broad spectrum of functional groups, including amines, alkenes, esters, alkynes, ethers, and nitriles. Furthermore, an alkyl bromide can be cross-coupled selectively in the presence of an alkyl chloride (equation D). Not only alkylboranes (entries 1-6), but also vinylboranes (entry 7), serve as suitable coupling partners.

This method for Suzuki coupling of alkyl bromides has been employed by others, e.g., by Phillips to achieve late-stage fragment couplings in natural-product total synthesis (Scheme 2). ${ }^{8}$

\section{Appendix}

\section{Chemical Abstracts Nomenclature; (Registry Number)}

\author{
8-Bromo-1-octanol: 1-Octanol, 8-bromo-; (50816-19-8)
}

\footnotetext{
${ }^{15}$ Column chromatography was performed on Kanto Chemical Silica Gel $60 \mathrm{~N}$ (wet packed in hexanes; $7 \mathrm{~cm}$ diameter $\times 13 \mathrm{~cm}$ height; $200 \mathrm{~g}$ ), eluting with a gradient of $\mathrm{CH}_{2} \mathrm{Cl}_{2}$ in hexanes $\left(500 \mathrm{~mL}\right.$ of hexanes, $500 \mathrm{~mL}$ of $5 \% \mathrm{CH}_{2} \mathrm{Cl}_{2} /$ hexanes, $1.0 \mathrm{~L}$ of $10 \% \mathrm{CH}_{2} \mathrm{Cl}_{2} /$ hexanes, $1.0 \mathrm{~L}$ of $15 \% \mathrm{CH}_{2} \mathrm{Cl}_{2} /$ hexanes; 100 -mL fractions). All the fractions (8-26) containing the desired product were combined

and concentrated by rotary evaporation $\left(20 \mathrm{mmHg}, 30^{\circ} \mathrm{C}\right)$. $\operatorname{NMR}\left(\mathrm{CDCl}_{3}, 400 \mathrm{MHz}\right) \delta: 0.60(\mathrm{q}, J=8.0 \mathrm{~Hz}, 6 \mathrm{H}), 0.96(\mathrm{t}, J=8.0 \mathrm{~Hz}, 9 \mathrm{H}), 1.26-1.28(\mathrm{~m}, 16 \mathrm{H}), 1.39-1.45(\mathrm{~m}, 2 \mathrm{H}), 1.50-1.56$ $(\mathrm{m}, 2 \mathrm{H}), 1.73-1.80(\mathrm{~m}, 2 \mathrm{H}), 3.53(\mathrm{t}, J=6.8 \mathrm{~Hz}, 2 \mathrm{H}), 3.59(\mathrm{t}, J=6.4 \mathrm{~Hz}, 2 \mathrm{H}) ;{ }^{13} \mathrm{C}$ NMR $\left(\mathrm{CDCl}_{3}, 100 \mathrm{MHz}\right) \delta: 4.4,6.8,25.8,26.9$, 28.9, 29.47, 29.54, 29.59, 29.60, 29.62, 32.6, 32.9, 45.2, 63.0; LRMS (DART) $\mathrm{m} / z$ calcd. for $\mathrm{C}_{19} \mathrm{H}_{42} \mathrm{ClOSi}\left([\mathrm{M}+\mathrm{H}]^{+}\right.$) 349.3 , found 349.3; Anal. calcd. for $\mathrm{C}_{11} \mathrm{H}_{24} \mathrm{OSi}$ : $\mathrm{C}, 65.93 ; \mathrm{H}, 12.07 ; \mathrm{N}, 0$; found: $\mathrm{C}, 65.99 ; \mathrm{H}, 11.80 ; \mathrm{N}, 0$. The spectral data are in agreement with the reported values. ${ }^{2}$
} 
Dichlorotriphenylphosphorane: Phosphorane, dichlorotriphenyl-; (2526-64-9)

Imidazole: 1H-Imidazole; (288-32-4)

1-Bromo-8-chlorooctane: Octane, 1-bromo-8-chloro-; (28598-82-5)

4-Penten-1-ol; (821-09-0)

Chlorotriethylsilane: Silane, chlorotriethyl-; (994-30-9)

Triethyl(pent-4-enyloxy)silane: Silane, triethyl(4-penten-1-yloxy)-; (374755-00-7)

9-BBN: 9-Borabicyclo[3.3.1]nonane; (280-64-8)

(5-(9-Borabicyclo[3.3.1]nonan-9-yl)pentyloxy)triethylsilane: 9-Borabicyclo[3.3.1]nonane, 9-[5-[(triethylsilyl)oxy]pentyl]-; (157123-09-6)

Palladium(II) acetate: Acetic acid, palladium(2+) salt (2:1); (3375-31-3)

Tricyclohexylphosphine: Phosphine, tricyclohexyl-; (2622-14-2)

Tripotassium phosphate, monohydrate: Phosphoric acid, tripotassium salt, monohydrate (8CI,9CI); (27176-10-9)

(13-Chlorotridecyloxy)triethylsilane: Silane, [(13-chlorotridecyl)oxy]triethyl-; (374754-99-1)

\section{Biography}

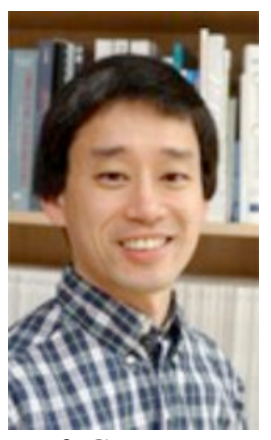

Prof. Greg Fu was born in Galion, Ohio, in 1963. He received a B.S. degree in 1985 from MIT, where he worked in the laboratory of Prof. K. Barry Sharpless. After earning a Ph.D. from Harvard in 1991 under the guidance of Prof. David A. Evans, he spent two years as a postdoctoral fellow with Prof. Robert H. Grubbs at Caltech. In 1993, he returned to MIT, where he is currently the Firmenich Professor of Chemistry. Prof. Fu received the Springer Award in Organometallic Chemistry in 2001, the Corey Award of the American Chemical Society in 2004, and the Mukaiyama Award of the Society of Synthetic Organic Chemistry of Japan in 2006. He is a fellow of the Royal Society of Chemistry and of the American Academy of Arts and Sciences. Prof. Fu serves as an associate editor of the Journal of the American Chemical Society. His current research interests include metal-catalyzed coupling reactions, chiral-ligand design, and enantioselective nucleophilic catalysis. 


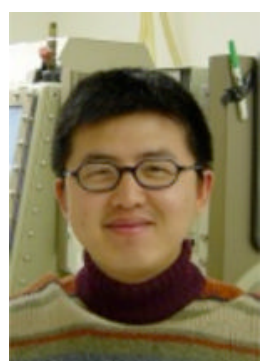

Sha Lou was born in He Bei, China, in 1979. He received a B.S. in Chemistry from Beijing University of Chemical Technology in 2002, where he conducted undergraduate research in fullerene functionalizations with Professor Shenyi, Yu. He obtained a Ph.D. degree in January 2008 from Boston University under the direction of Professor Scott E. Schaus. His graduate research has focused on transition metal- and organic molecule-catalyzed asymmetric carbon-carbon bond forming reactions and synthesis. In 2008, he joined the group of Professor Greg Fu at MIT as a postdoctoral fellow. His current research involves the development of transition metal-catalyzed enantioselective cross-coupling reactions.

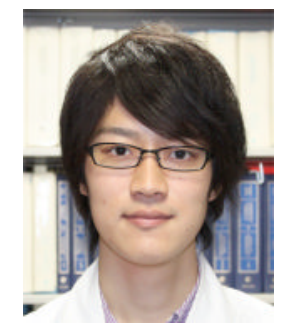

Takuya Higo was born in Saga, Japan in 1986. He received his B.S. in 2009 from the University of Tokyo. In the same year, he began his graduate studies at the Graduate School of Pharmaceutical Sciences, the University of Tokyo, under the guidance of Professor Tohru Fukuyama. His research interests are in the area of the total synthesis of natural products.

\section{References}

1. Department of Chemistry, Room 18-290, Massachusetts Institute of Technology, Cambridge, Massachusetts 02139; gcf@mit.edu.

2. Netherton MR, Dai C, Neuschütz K, Fu GC. J. Am. Chem. Soc 2001;123:10099-10100. [PubMed: 11592890]

3. For some leading references, see: a de Meijere, A.; Diederich, F., editors. Metal-Catalyzed CrossCoupling Reactions. Wiley-VCH; New York: 2004. b Miyaura, N., editor. Topics in Current Chemistry. Springer-Verlag; New York: 2002. Cross-Coupling Reactions: A Practical Guide. Series 219c Negishi, E.-i., editor. Handbook of Organopalladium Chemistry for Organic Synthesis. Wiley Interscience; New York: 2002.

4. For overviews, see: a Frisch AC, Beller M. Angew. Chem., Int. Ed 2005;44:674-688.b Netherton, MR.; Fu, GC. Topics in Organometallic Chemistry: Palladium in Organic Synthesis. Tsuji, J., editor. Springer; New York: 2005. p. 85-108.

5. Ishiyama T, Abe S, Miyaura N, Suzuki A. Chem. Lett 1992:691-694.

6. a Kirchhoff JH, Dai C, Fu GC. Angew. Chem., Int. Ed 2002;41:1945-1947. b Netherton MR, Fu GC. Angew. Chem., Int. Ed 2002;41:3910-3912. c Kirchhoff JH, Netherton MR, Hills ID, Fu GC. J. Am. Chem. Soc 2002;124:13662-13663. [PubMed: 12431081]

7. For mechanistic studies, see: ${ }^{a}$ References ${ }^{2}$ and ${ }^{6}$. Hills ID, Netherton MR, Fu GC. Angew. Chem., Int. Ed 2003;42:5749-5752.

8. a Keaton KA, Phillips AJ. Org. Lett 2007;9:2717-2719. [PubMed: 17559220] b Griggs ND, Phillips AJ. Org. Lett 2008;10:4955-4957. [PubMed: 18844364] 


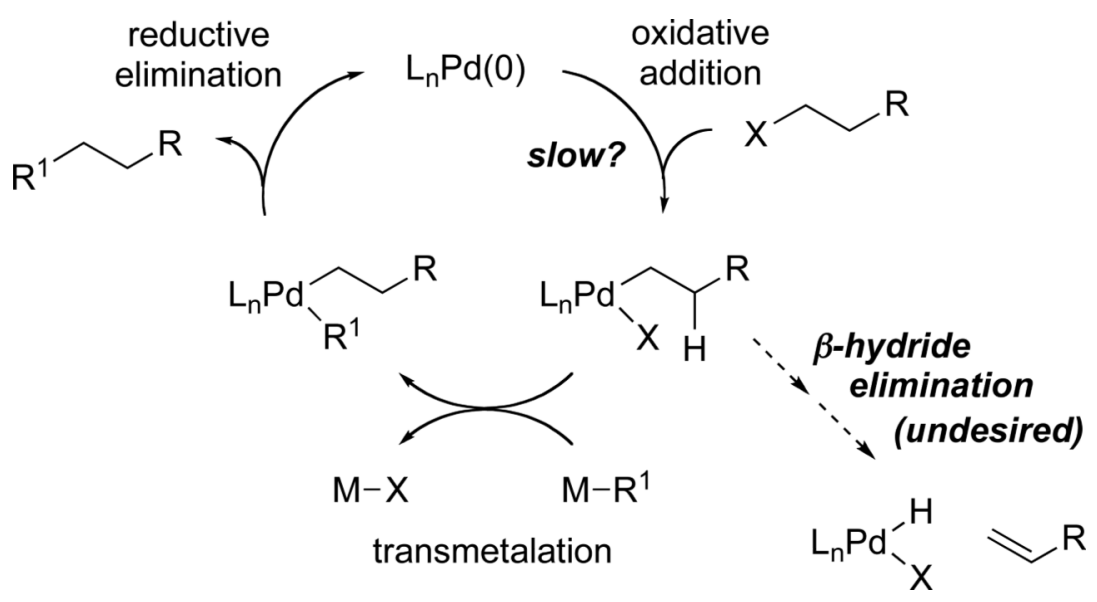

Scheme 1.

A Generalized Mechanism for Palladium-Catalyzed Cross-Coupling of an Alkyl Electrophile. 
(+)-Spirolaxine methyl ether
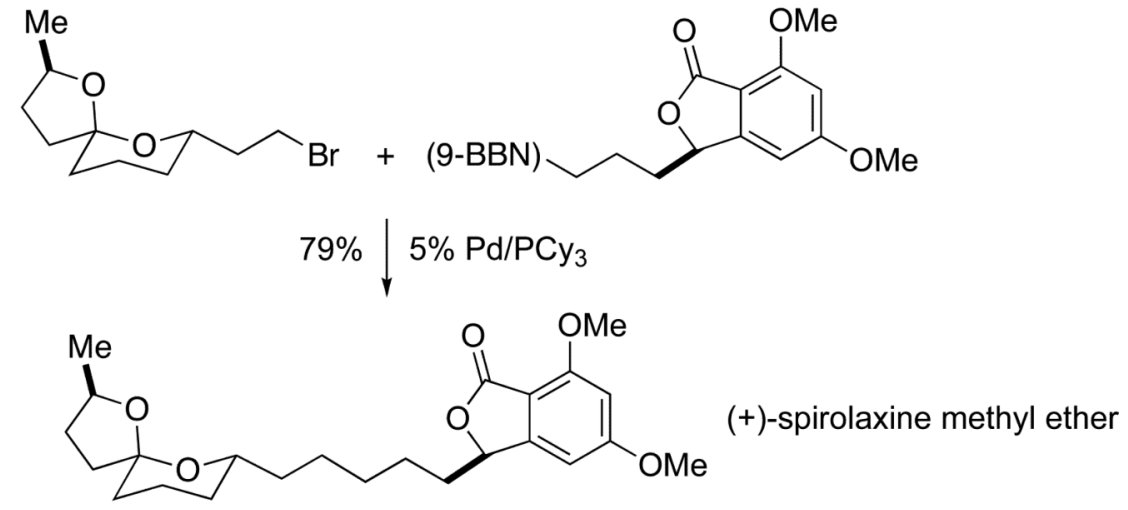

(+)-Pyranicin
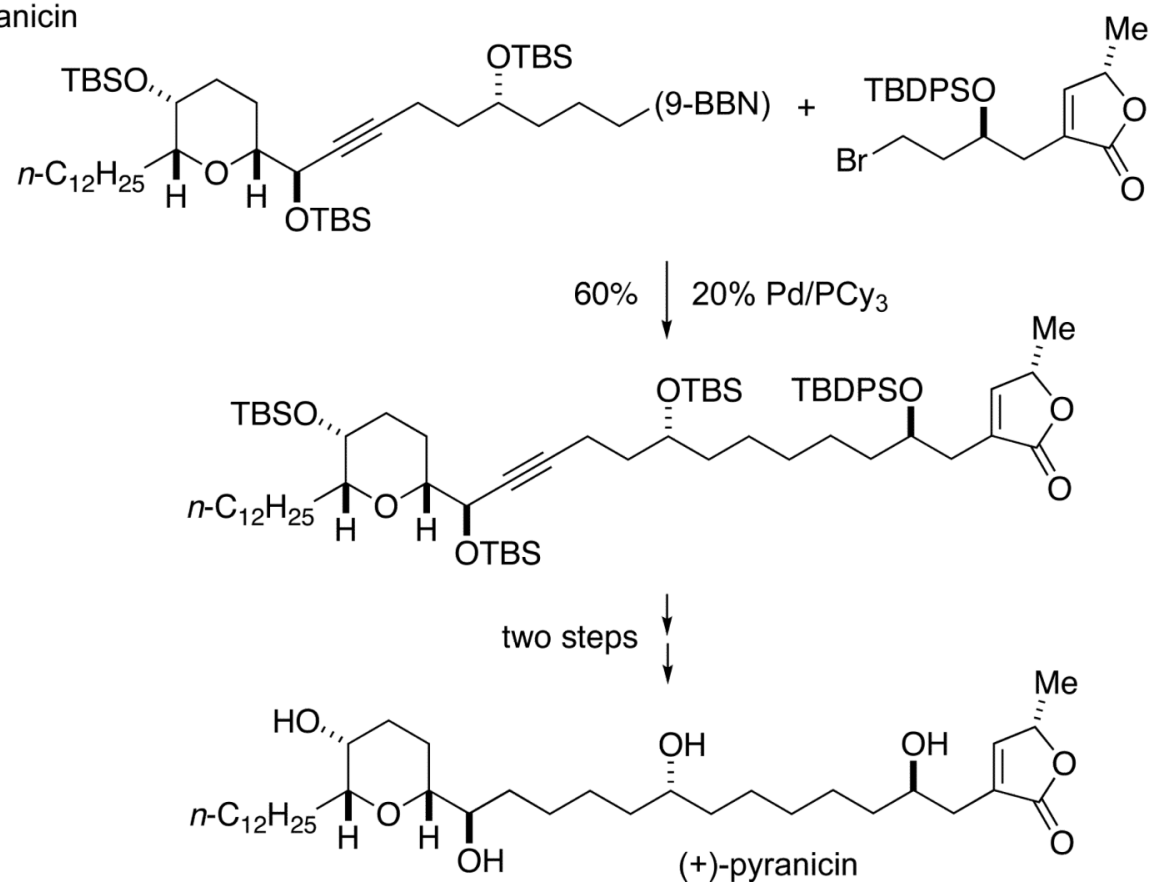

Scheme 2.

Applications in Total Synthesis of $\mathrm{Pd} / \mathrm{PCy}_{3}$-Catalyzed Alkyl-Alkyl Suzuki Reactions: Fragment Couplings. 


\section{Table 1}

$\mathrm{Pd} / \mathrm{PCy}_{3}-$ Catalyzed Suzuki Cross-Couplings of Unactivated Alkyl Bromides at Room Temperature.

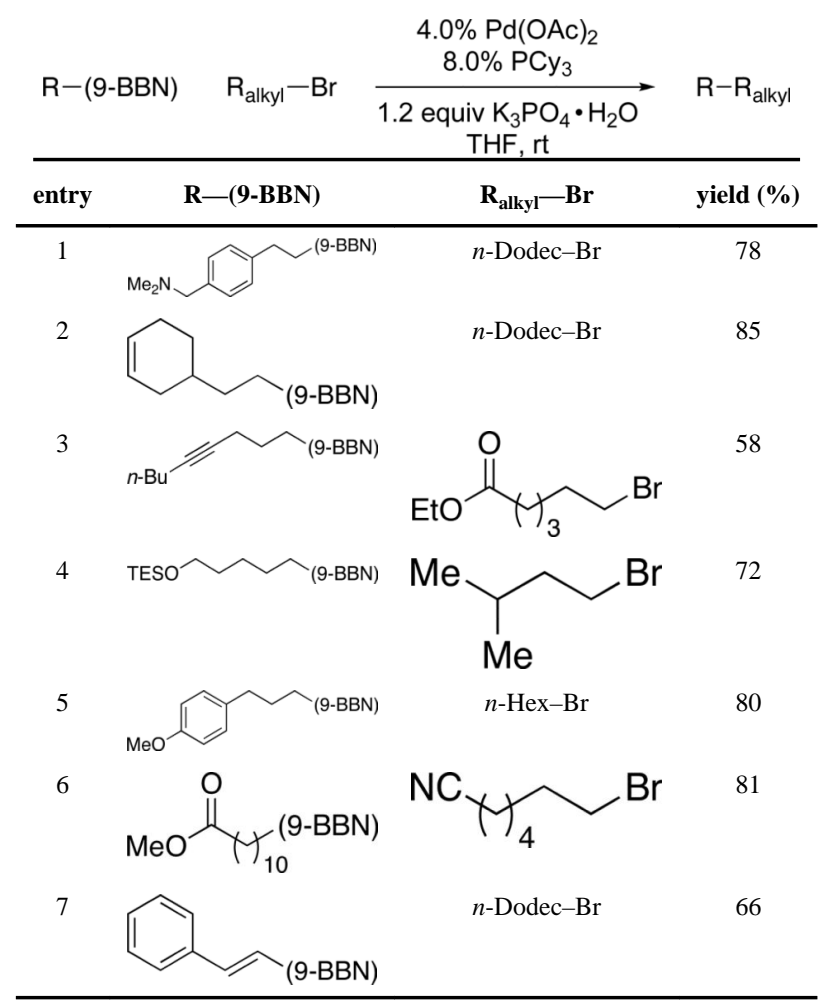

